MATEC Web of Conferences 6, 01003 (2013)

DOI: $10.1051 /$ matecconf/20130601003

(C) Owned by the authors, published by EDP Sciences, 2013

\title{
Spalling tests on embedded cores and slabs: A comparative study
}

\author{
P. Pimienta ${ }^{1}$, B. Moreau ${ }^{2}$, R. Avenel ${ }^{1}$, P. Peyrac ${ }^{3}$, N. Taillefer ${ }^{1}$, C. Larive ${ }^{2}$, \\ L. D'Aloia ${ }^{2}$ and P. Clec'h ${ }^{3}$ \\ ${ }^{1}$ CSTB, Marne la Vallée, France \\ ${ }^{2}$ CETU, Bron, France \\ ${ }^{3}$ DRIEA-IF - Département ingénierie Ouvrages d’Art, le Pré Saint Gervais, France
}

\begin{abstract}
A comparative analysis of the spalling of (a) cores made of 3 concrete mixes embedded into 3 slabs made of the 3 same concrete mixes; and (b) 3 reference slabs made again of the same 3 concrete mixes has been made. Samples have been exposed to the French Increased HydroCarbon temperature curve. Results confirm that concrete spalling phenomena is not only related to the material properties. Concrete spalling is also very much influenced by the geometry of the samples.
\end{abstract}

\section{INTRODUCTION}

Concrete spalling phenomenon is not only related to the materials' properties but also very much influenced by the geometry of the samples and other parameters like the heating rate. Indeed, changes in internal stresses, temperature gradients, vapour and liquid transport upon heating, depend on the geometry and affect concrete spalling [1-3]. When assessing the spalling risk of a concrete structure, testing elements with geometry and mechanical boundary conditions as close as possible to the real structural layout, is then necessary. However, this can be difficult in some situations, as for example when assessing existing structures.

Test methods on small samples and specially designed in order to reproduce the thermo-hydromechanical conditions of the concrete in real structure have been proposed by Hertz [4]. Tests were carried out on concrete cylinder surrounded by a steel tube designed to restrained thermal expansion.

This research aims to assess new testing methodology, based on a similar scheme. Tests are carried out on cores taken from existing structures. Cores are embedded in a concrete slab with an anchoring mortar (Fig. 1). The slabs are then tested on a horizontal furnace for 2 hours.

The objective of this experimental study was to assess if the spalling of embedded cores is representative of the spalling of a slab of the same concrete, and if the fire behaviour of the slab in which are embedded the cores influences the spalling of the cores.

This paper focuses particularly on tunnel structures. Samples have been exposed to the Increased HydroCarbon temperature curve, HCinc. The HCinc curve was introduced in the French tunnel regulation after the dramatic fire in the Mont-Blanc tunnel (between France and Italy) in March 1999. This curve is based on the hydrocarbon curve of Eurocode part 1 part 1-2 [5]. It was changed by putting its asymptote at $1300^{\circ} \mathrm{C}$ (Eq. (1)).

$$
T=20+1280\left(1-0.325 e^{-0.167 \tau}-0.675 e^{-2.5 \tau}\right) .
$$

A more detailed presentation of the curve and its genesis and an overview of ten-year experience acquired in France are presented in [6].

This is an Open Access article distributed under the terms of the Creative Commons Attribution License 2.0, which permits unrestricted use, distribution, and reproduction in any medium, provided the original work is properly cited. 


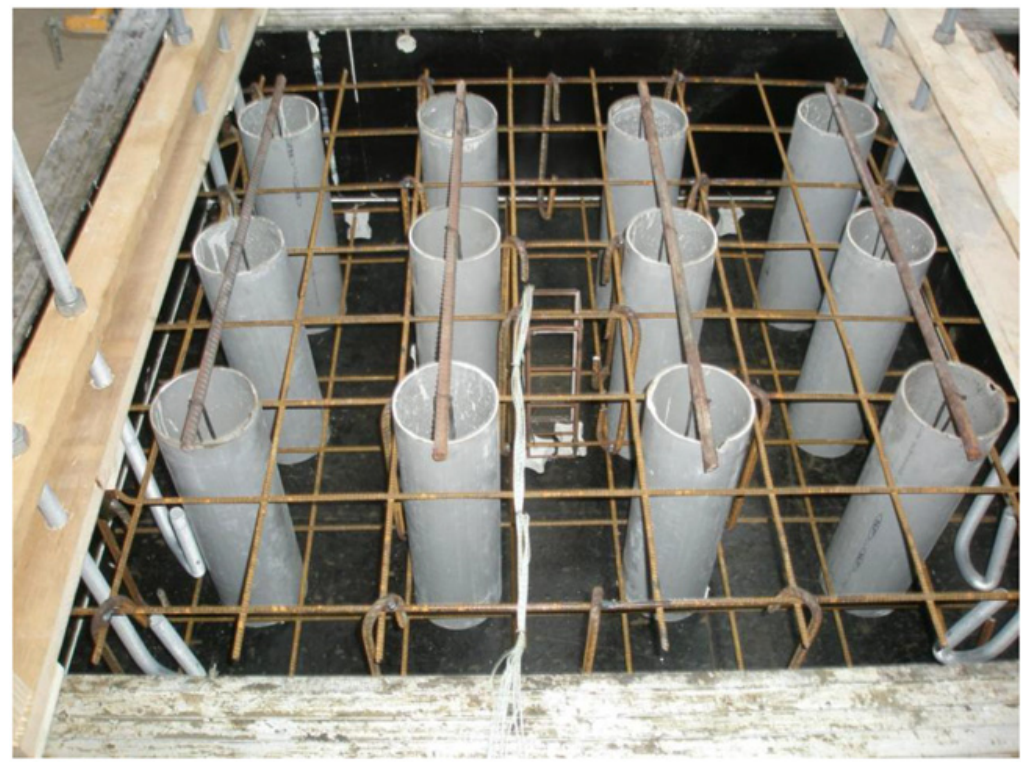

Figure 1. Pictures of the slab in which will be embedded cores, before the casting.

\section{EXPERIMENTAL SETUP}

To reach the research program objectives, a comparative analysis of the spalling of (a) cores made of 3 concrete mixes embedded into 3 slabs made of the 3 same concrete mixes; and (b) 3 reference slabs made again of the same 3 concrete mixes has been made (Fig. 2).

\subsection{Concrete mixes}

The first step of this study was to choose 3 mixes of concrete. These 3 concretes, called F1, F2 and F3 were designed in order to achieve a range of sensitivity to spalling, respectively low, medium and high when they are exposed to the Increased Hydrocarbon curves (HCinc). F1 is a B40 with polypropylene fibres. F2 is the same B40 but without polypropylene fibres. And F3 is a C50/60.

Preliminary fire tests have been carried out to check the real spalling of the 3 concretes.

Concretes compositions and properties are given in Table 1. F1 and F2 concretes have been cast in the laboratory. They are the same concretes except that F1 contains Adfil polypropylene fibres (length: $12 \mathrm{~mm}$ and diameter $=18 \mu \mathrm{m}$ ) in order to reduce the spalling risk. They are made of CEM II/A-LL 42.5 R CE PM CP2 NF, sand 0/2 and calcareous aggregates 8/12.5 and 12.5/20. F1 and F2 concretes have been extensively studied under respectively the names B40F and B40 [7]. F3 concrete have been fabricated in a ready mix plant and delivered to the laboratory to be cast. It contains CEM I 52,5 N CE CP2 NF, condensed silica fume, limestone filler, limestone sand 0/4 and aggregates 4/10 and 6.3/20.

\subsection{Test specimens}

Six slabs of $1,26 \mathrm{~m} \times 1,42 \mathrm{~m} \times 0,40 \mathrm{~m}$ and 36 cores of $400 \mathrm{~mm}$ high and $121 \mathrm{~mm}$ diameter were made; 2 slabs and 12 cores per concrete mix. 3 slabs were used as a reference to assess the concrete spalling. In the 3 other slabs, 12 cores were embedded (4 cores of each concrete) in the holes that were made during the casting of these slabs (Fig. 1).

The cores were sealed in the slabs with a fire resistant mortar ("Fire Barrier" type mortar). As the holes in the slabs had a diameter of $125 \mathrm{~mm}$, the mortar thickness was $2 \mathrm{~mm}$ in average. 
Table 1. Concrete compositions and properties.

\begin{tabular}{|l|c|c|c|}
\hline & F1 & F2 & F3 \\
\hline Cement $\left(\mathrm{kg} / \mathrm{m}^{3}\right)$ & 347 & 347 & 390 \\
\hline Silica fume $\left(\mathrm{kg} / \mathrm{m}^{3}\right)$ & & & 30 \\
\hline Limestone filler $\left(\mathrm{kg} / \mathrm{m}^{3}\right)$ & & & 50 \\
\hline $0 / 2$ alluvial rounded sand $\left(\mathrm{kg} / \mathrm{m}^{3}\right)$ & 838 & 838 & \\
\hline $8 / 12.5$ limestone gravel $\left(\mathrm{kg} / \mathrm{m}^{3}\right)$ & 327 & 327 & \\
\hline $12.5 / 20$ limestone gravel $\left(\mathrm{kg} / \mathrm{m}^{3}\right)$ & 714 & 714 & \\
\hline $0 / 4$ limestone sand $\left(\mathrm{kg} / \mathrm{m}^{3}\right)$ & & & 780 \\
\hline $4 / 10$ limestone gravel $\left(\mathrm{kg} / \mathrm{m}^{3}\right)$ & & & 400 \\
\hline $6.3 / 20$ limestone gravel $\left(\mathrm{kg} / \mathrm{m}^{3}\right)$ & & & 500 \\
\hline Superplasticizer $\left(\mathrm{kg} / \mathrm{m}^{3}\right)$ & 5 & 2 & 3.9 \\
\hline Polypropylene fibres $\left(\mathrm{kg} / \mathrm{m}^{3}\right)$ & 2 & & \\
\hline Water & 186 & 186 & 160 \\
\hline Slump (mm) & 75 & 130 & $145-165$ \\
\hline Compressive strength at age $>90$ days $(\mathrm{MPa})$ & 35.5 & 36.0 & 66.5 \\
\hline
\end{tabular}
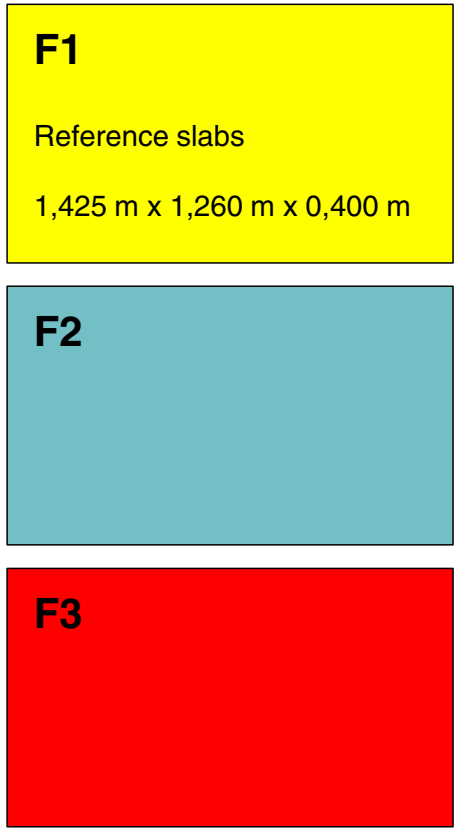
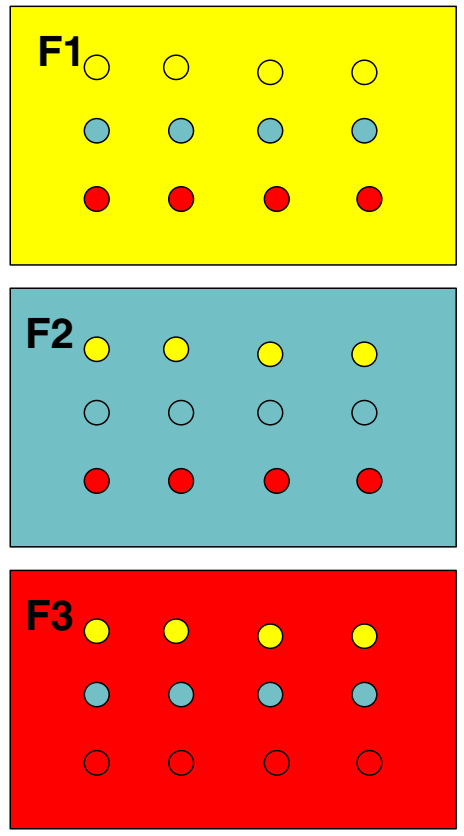

Figure 2. Schematic representation of the test program with the 3 reference slabs (on the left) and the 3 slabs with embedded cores (on the right).

\subsection{Fire test}

The 6 slabs were horizontally tested all together in the $4 \mathrm{~m} \times 3 \mathrm{~m}$ CSTB furnace and exposed to the Increased HydroCarbon temperature curve, HCinc, for 2 hours.

Figure 2 shows a schematic representation of the tested slabs and cores. 


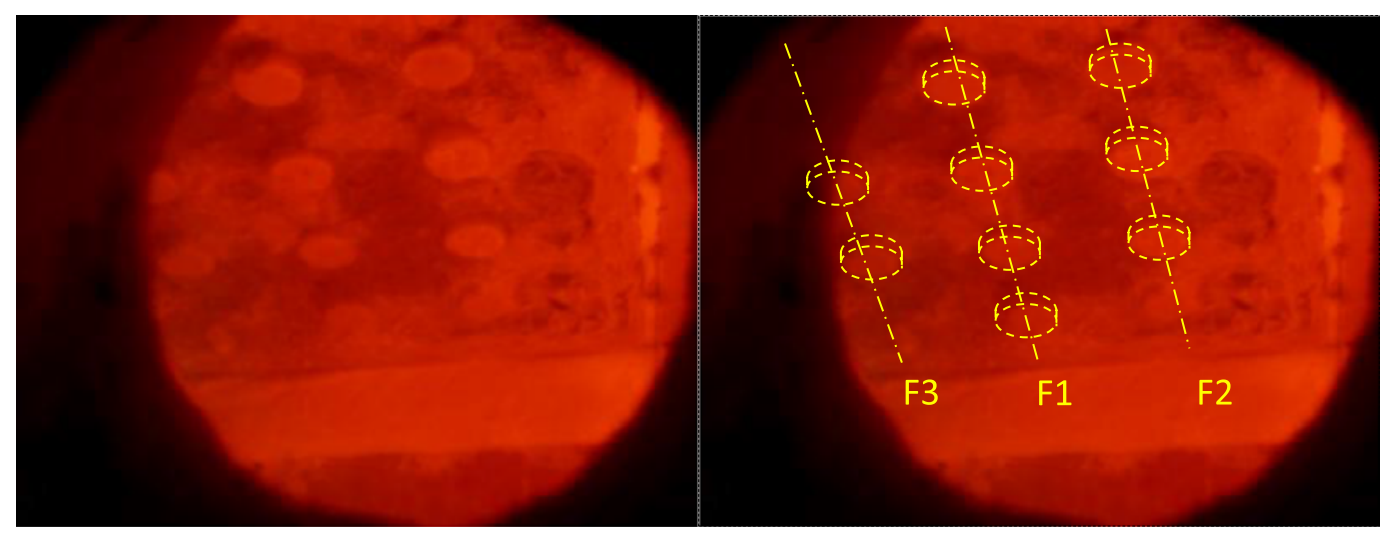

Figure 3. Pictures of the embedded F3 slab during the spalling test after $25 \mathrm{~min}$; the draws in the right indicate the position of the cores made with the 3 concretes.

\section{TEST RESULTS}

Observations during the fire test and spalling depths measured after the test are presented below and will be discussed in section 4 .

\subsection{Observations during the spalling test}

Observations during the spalling test were made through small windows of the furnace. An example of picture taken through the furnace window is presented in Figure 3.

Slabs made of F1 concrete did not spall. However, a dark layer of melted material appeared at the slab surfaces. The formation of a glassy layer has been observed during research and commercial tests carried in CSTB in France, SP in Sweden and MFPA in Germany (Dehn, personal communication) when exposing concrete with siliceous sand to HCinc and RWS curves.

Spalling occurred for the F2 slabs between 5 and 12 minutes and for the F3 slabs for the first half of hour of the test.

During the test, cores embedded in slabs that spalled (F2 and F3) appeared to be jutted out (Fig. 3). The cores behaved differently from the slabs. Spalling occurred on the slabs but not on the cores. In slab F3, which amount of spalling was higher, visual observation showed that the cores thickness decreased very slowly with the time by erosion of the concrete. This phenomenon of erosion lasted for the all duration of the spalling test.

\subsection{Measurements after the spalling test}

Spalling depths were measured after the test. Measures have been taken on a $15 \mathrm{~cm} \times 15 \mathrm{~cm}$ grid on the slabs and on 17 points for each cores' surface. It should be mentioned that during the cooling phase materials fell off the tested elements. In particular, the dark layer appeared at the surface of the F1 concrete fell down. In this context, the measure of the reduction of thickness after the test includes every phenomenon that resulted in a loss of material whether it happened during the heating phase or the cooling phase (spalling, erosion, detachment due to re-hydration, carbonation ...).

Average spalling depths are presented on Figure 5. The X-axis indicates the element on which the spalling is measured. And the Y-axis indicates the concrete (F1, F2 or F3) of the plain or embedded slab.

Concerning the spalling of the plain and embedded slabs, it can be noticed that it increases from F1 to F3 which is what was expected. The embedded F1 and F3 slabs give approximately the same results 


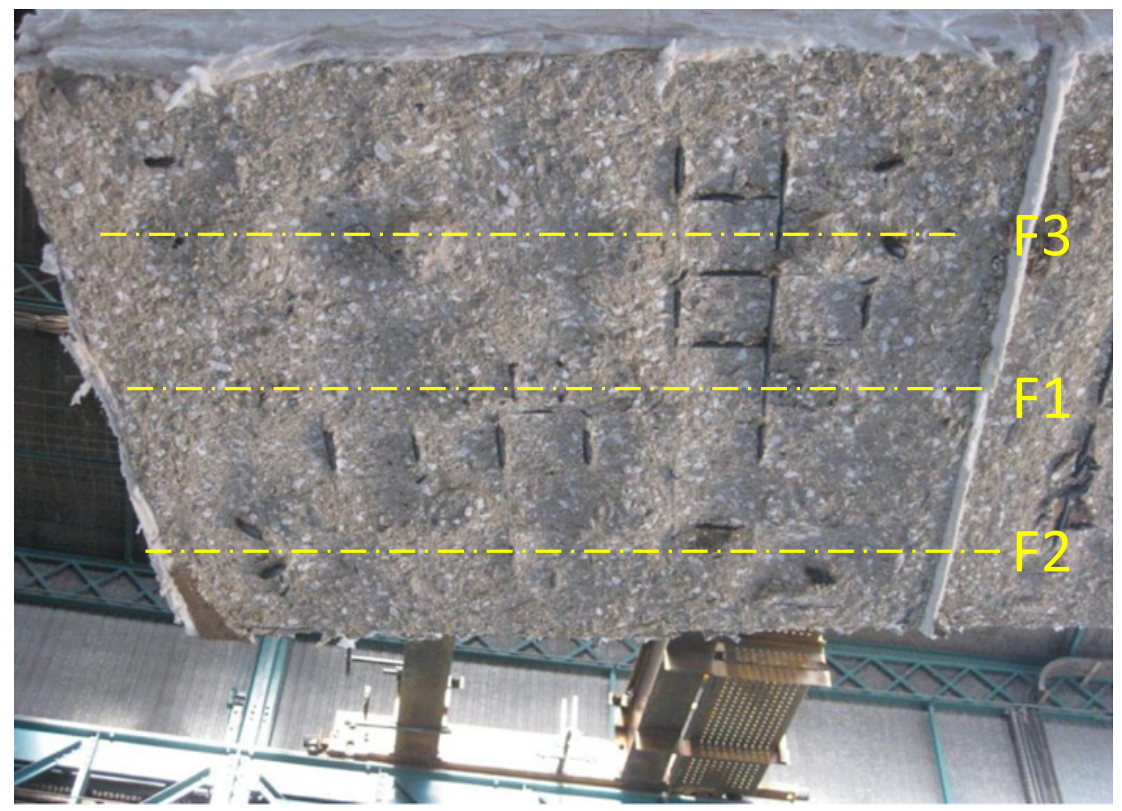

Figure 4. Picture of the embedded F3 slab after the spalling test.

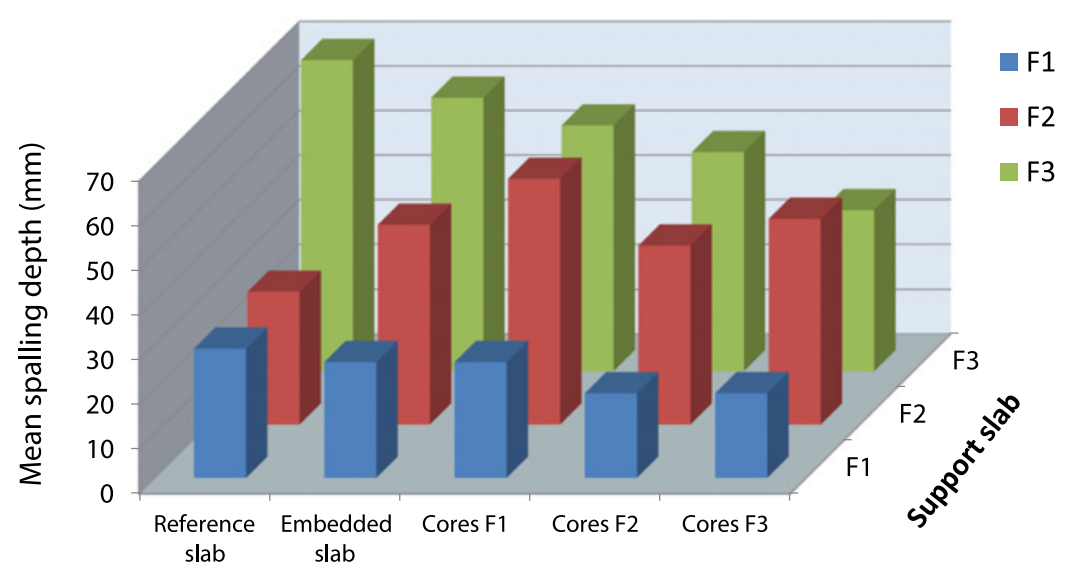

Figure 5. Spalling depths of the embedded cores and slabs.

as the two F1 and F3 reference slabs. However, the embedded F2 slab spalled more than the F2 reference slab.

Comparison of the results shows that spalling behaviour of the cores can be very different compare to the spalling behaviour of the slabs made with the same concrete. In particular, we can comment on three cases. The spalling depth of the F3 cores in the F1 slab is very close to the spalling depth of the F1 slab but much smaller than the spalling depth of the F3 slab. The same results can be drawn for the F1 cores in the F3 slab: spalling depth of the F1 cores are very close to the F3 slab in which they are embedded, and significantly different from the spalling depth of the F1 slab. Finally, looking at the spalling depths of the embedded F3 slab, we can notice that the F3 cores spalled less than the F1 and F2 cores and the F3 slabs. The opposite result would have been expected. 
MATEC Web of Conferences
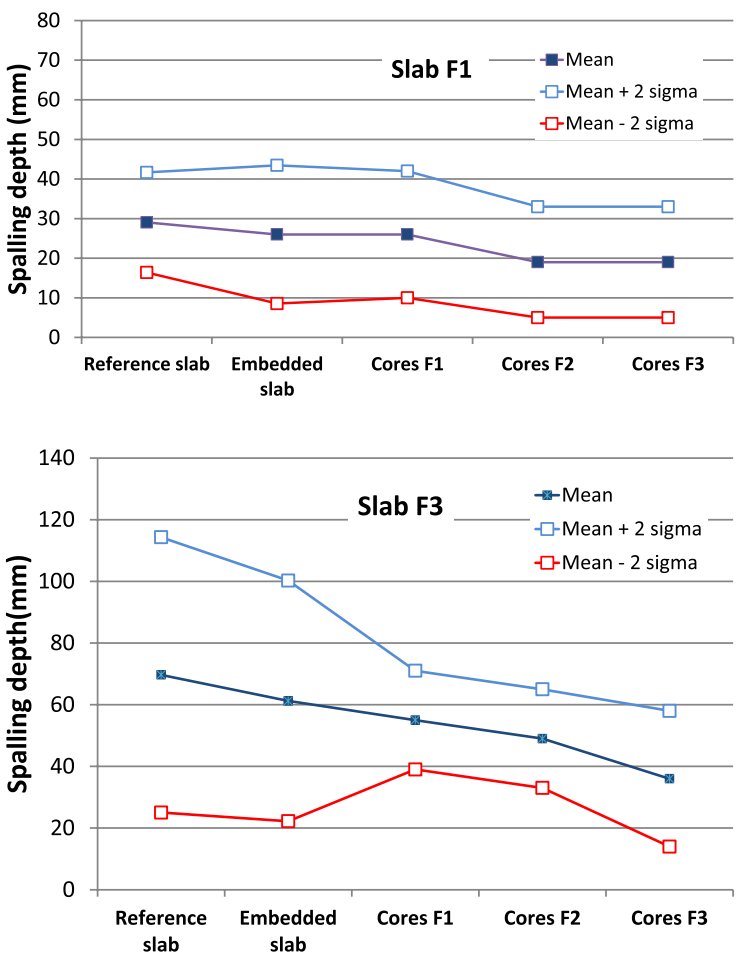

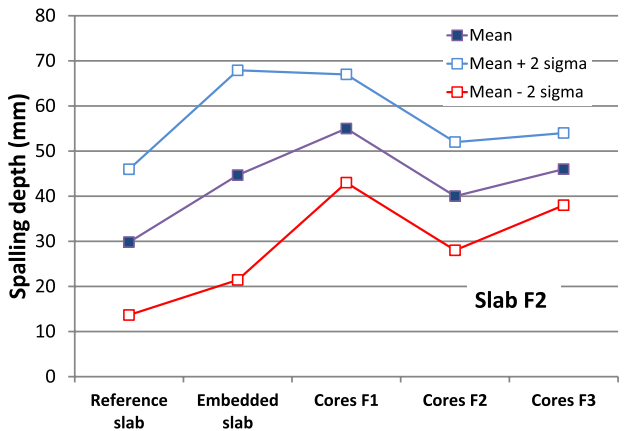

slab

Figure 6. Spalling depths of the embedded cores and slabs; mean value and mean value \pm 2 standard deviations.

Figure 6 represents the same results as Figure 5 but taking the standard deviation of each value into account. We observe that, although not negligible, the scattering of the results does not change the analysis made previously. Spalling of the cores is not always the same as the slabs made with the same concrete and depends on the slab in which they are embedded.

From Figure 5 analyse, it appears that the mean spalling depths of F1 and F3 cores are higher than the ones of F2 slab in which the cores are embedded. This was not observed during the spalling test. In order to precisely analyse the influence of the slab on the embedded cores, Figure 7 compares the spalling depth of the cores to the spalling depth of the slab measured around the embedded cores. Contrary to Figures 5 and 6 which show the average spalling depth over the entire concrete slab surface, Figure 7 represents the spalling of the embedded slab localized around the embedded cores.

This figure shows that the cores embedded in the F2 slab are in fact slightly jutted out the slab surface. Also, it clearly shows that the spalling depths of all the cores in the F1 and F2 slabs are very similar to the spalling depths of the respective F1 and F2 embedded slabs. Only part of the cores in the F3 slabs is significantly jutted out the slab surface.

\section{DISCUSSION}

One of the main outcomes from our experiments is that cores do not exhibit the same spalling behaviour than the slabs (reference slabs and embedded slabs). For example, we have observed important spalling activity in the slabs F3 from the first minutes. On the other hand, for much of the test, cores did not spall and appeared to be jutted out.

Among the hypotheses on the process leading to spalling, two hypotheses are largely considered today. The first is thermo-mechanical and is essentially based on the differential dimensional constraints 


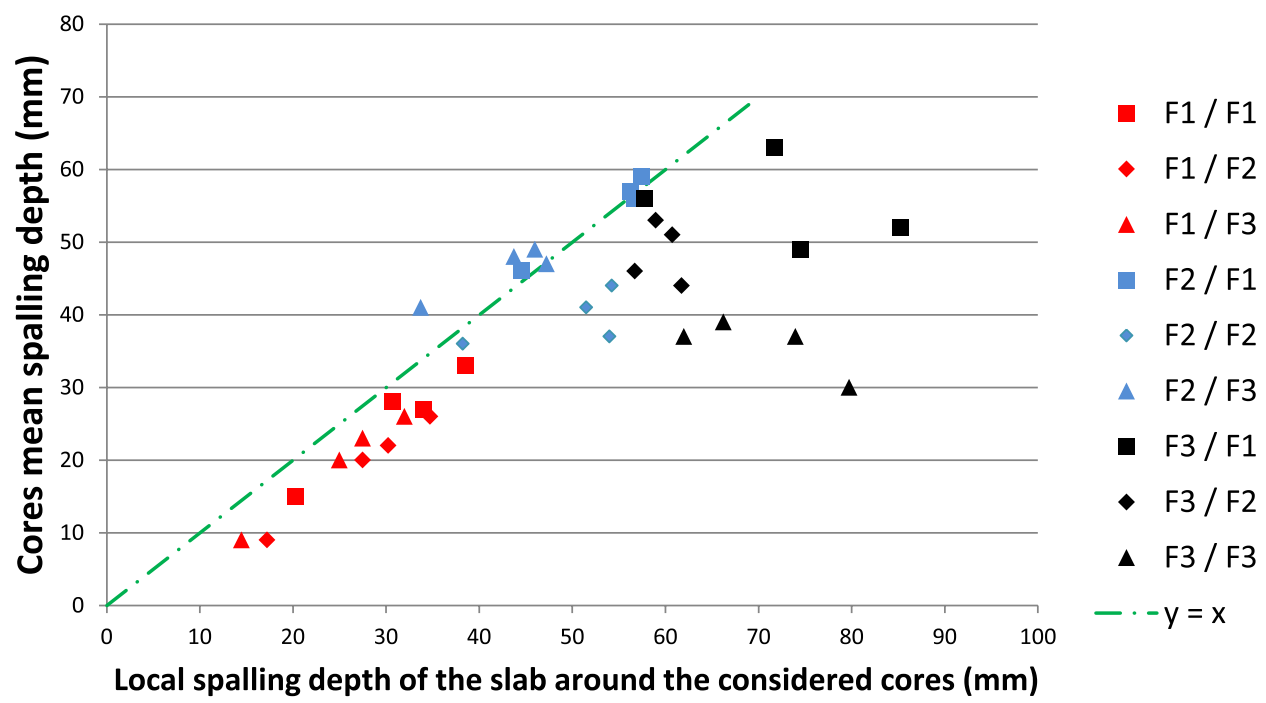

Figure 7. Comparison of the spalling depth of the embedded cores and the spalling depth of the slab around these cores.

developed during exposure to high temperature $[8,9]$. When considering this mechanism, the spalling risk is then largely dependent on the thermal gradients in the first centimetres of the concrete where spalling occurs and then on the samples geometry.

The second is thermo-hydric and considers that the pores water vapour pressures developed when the structure is exposed to a heating are responsible for the thermal instability of the concrete [3]. Spalling is certainly caused by the combination of the two mechanisms in varying proportions, depending on the situation.

The operating principle of the test on embedded cores in slabs is to recreate a stress state in the cores representative of the ones in the real slab. However, there is not a perfect contact between the cores and the embedded slabs. Cores are connected to the slabs with a fire resistant mortar which for example does not have the same thermal expansion characteristics as the concrete. Stresses in the cores are therefore certainly different than the ones in the concrete slabs.

Spalling of the embedded slab F3 was much faster and deeper than the one of F1 and F2 slabs. We have observed that spalling of jutted out cores occurred later and was slower and more progressive than the one of the F3 slab which was faster and more violent. This spalling velocity difference can explain that cores embedded in concrete slab F3 were still jutted out at the end of the test.

It has also been observed that in embedded slab F3, spalling rate of cores F3 was slower than the one of F1 and F2. Based on this observation, it is proposed that the spalling mechanism of the cores in the slab F3 is not the same than the one of the slabs. The material loss in the cores is attributed to an erosion of the concrete exposed to the very high temperature of the furnace and not to violent expulsed material particles as in the slabs. This mechanism is consistent with the slower loss of material in F3 cores which concrete is more compact and therefore more resistant. Due to their lower rate of erosion some cores did not had time to erode during the test to the level of the slab F3 spalling depth (deeper than slabs F1 and F2 spalling depth). From our observations, we then propose that the mechanisms of material loss of the jutted out cores (which are exposed to more heat than the slabs) and of the slab spalling are different. 


\section{MATEC Web of Conferences}

\section{CONCLUSION}

The most important findings of this research are the following.

- Cores do not exhibit the same spalling behaviour than the slabs (reference slabs and embedded slabs).

- Spalling depth of the embedded slabs measured after the test strongly influences the ones of the cores.

- We propose that the mechanisms of material loss of the jutted out cores (which are exposed to more heat than the slabs) and of the slab spalling are different.

Our findings are consistent with the models which have been presented above. The spalling phenomena depend not only on the material properties and the thermal load, but also on thermal stresses that develop in the concrete and therefore the geometry of the tested samples.

It is important to keep in mind that spalling depth measured after test is the total amount of detached concrete from the slabs and the cores after cooling. Thus, the measured values take into account all phenomena occurring during and after the heating.

\section{References}

[1] Zhukov, Explosive failure of concrete during a fire (in Russian), Translation No. DT 2124, Joint Fire Research Organisation, Borehamwood, 1975.

[2] Bazant Z. P., Kaplan M. F., Concrete at High Temperatures: Material Properties and Mathematical Models, Pearson Education, 1996.

[3] Harmathy, T. Z., Effect of moisture on the fire endurance of building elements. Research paper 270, Ottawa, Division of Building Research, 1965.

[4] Hertz K. D., Sorensen L. S., Test method for spalling of fire exposed concrete, Fire safety journal, 2005, vol. 40, no 5, pp. 466-476.

[5] NF EN 1992-1-2 Eurocode 1: actions on structures - Part 1-2 : general actions - actions on the structures exposed to fire, July 2003.

[6] Taillefer N., Carlotti P., Larive C. ,Lemerle C., Avenel R., Pimienta P. Ten years of increased hydrocarbon temperature curves in French tunnels. Fire Technology. Volume 49, Issue 2, 531-549, 2013

[7] Mindeguia J.C., Pimienta P., Carre H., La Borderie C. Experimental analysis of concrete spalling due to fire exposure. European Journal of Environmental and Civil Engineering, 14 p. April 2013.

[8] Bazant ZP, Cusatis G, and Cedolin L. Temperature Effect on Concrete Creep Modelled by Microprestress-Solidification Theory. Journal of Engineering Mechanics 130(6): 691-699. 2004

[9] Sercombe J., Galle C., Durand S.F. and Bouniol P. On the importance of thermal gradients in the spalling of high-strength concrete 14th Engineering Mechanics Conference Austin, USA. 2000. 